\title{
ESTUDO NA OBTENÇÃO DE NÃOTECIDOS DE POLIAMIDA ATRAVÉS DA ELETROFIAÇÃO COM PROPRIEDADES ANTICHAMA
}

\author{
M. MARQUES ${ }^{1}$, R. B. VENTURELLI ${ }^{2}$, A.A.U.SOUZA², A.P.S.IMMICH ${ }^{1}$ \\ ${ }^{1}$ Universidade Estadual de Santa Catarina, Engenharia Têxtil, Blumenau - SC \\ ${ }^{2}$ Universidade Estadual de Santa Catarina, Departamento de Engenharia Química e \\ Engenharia de Alimentos, Florianópolis - SC \\ E-mail para contato: ana.immich@ufsc.br
}

\begin{abstract}
RESUMO - Dentro da ampla cadeia têxtil os tecidos técnicos são destinados a desempenhar funções específicas que vão além do mundo da moda. Os nãotecidos, uma subdivisão dos técnicos, se diferem por não serem constituídos pela trama dos fios. Eles são caracterizados por uma forma lamelar, elástica e flexível. Dentre as formas de fabricação dessa manta se encontra a eletrofiação. Esta técnica tem sido largamente estudada nos últimos anos por apresentar possibilidade de melhorar as propriedades do não tecido com aditivos nas nanofibras. Usando a poliamida como matéria-prima e a eletrofiação como método de confecção, este estudo conseguiu obter uma manta de nãotecido. A adição de $\mathrm{NaCl}$ a solução polimérica foi essencial para o sucesso da obtenção do jato do polímero e consequentemente a produção do nãotecido. Este nãotecido apresentou uma regularidade de fibras com diâmetro na escala nanométrica com um espaço interno tridimensional poroso, excelente para a adição de agentes modificadores de propriedades como agentes de repelência a chama, utilizado para funcionalização do nãotecido.
\end{abstract}

\section{INTRODUÇÃO}

Apesar das vestimentas terem surgido com a função de proteção nas épocas mais antigas, atualmente, roupas passaram a ser usadas como manifestação cultural e adorno. Porém, por trás dessa pequena parte da cadeia têxtil mais conhecida que é a moda, existe uma ampla estrutura que engloba muito além do vestuário convencional chamada de têxteis técnicos.

Segundo o manual desenvolvido pela Associação Brasileira de Nãotecidos e Tecidos Técnicos (ABINT), têxteis técnicos são materiais constituídos de matérias-primas na forma de fibras, fios, filamentos, etc., nos mais diferentes arranjos (flocos, fios, tecidos, nãotecidos) com aplicações que necessitem desempenho bem determinado, visando praticidade, segurança, economia e durabilidade definida, exceto os têxteis que são utilizados em moda, cama, mesa e banho.

Os tecidos são caracterizados pela trama de fios. Já o arranjo chamado de nãotecido caracteriza-se por ser uma manta com forma lamelar, elástica e flexível, de maior ou menor 
diferença. A manta pode ser formada por processo via seco, via húmido, por fusão e outros métodos especiais, como a eletrofiação.

Esta técnica é uma alternativa para produção de nãotecido e é conhecida a mais de 70 anos, porém com as recentes pesquisas em nanotecnologia ela voltou a ser amplamente explorada, afirmam Xia e Li (2004). A eletrofiação é uma técnica eficiente para produzir fios em escala nanométrica mediante diferença de potencial elétrico. Segundo Santos et al. (2011) a elevada área superficial desse nãotecido formado obtido pela eletrofiação favorece múltiplas aplicações técnicas na indústria farmacêutica, de saúde, eletrônica, automobilística, de filtração, etc. A escolha da utilização do processo de eletrofiação é influenciada pelo tipo do polímero a ser utilizado e a aplicação final.

Em sua fundamentação teórica sobre solução de polímeros para eletrofiação Costa et al. (2012) enfatiza os extensivos estudos que vem sido feitos com diversificados tipos de polímeros como poli(vinilpirrolidona), poli(álcool vinílico), poli(acido lático), e complementando, Santos et al. (2011) relatam a obtenção de nanocompósito por eletrofiação de poliamida 66.

Na técnica de eletrofiação a solução polimérica é mecanicamente bombeada através de um capilar conectado a um campo elétrico, deve superar a tensão superficial da solução atraindo o polímero até uma placa coletora (GOMES, 2014).

Dentre as vantagens da eletrofiação, a possibilidade de adicionar aditivos para modificar propriedades é uma das que mais se destaca. Assim, nosso trabalho visa estudar a modificação das propriedades antichama de um nãotecido de poliamida, processado por eletrofiação, que será incorporado como reforço para proteção em uniformes técnicos.

Roupas para proteção é uma área que apresenta baixo volume de consumo quando se analisa o consumo geral de tecidos técnicos por nicho de mercado. Em contra partida, mostra um alto valor unitário, movendo 5,2 bilhoes de dólares em 2000, exemplifica a associação especialista em fibras Rigby D (2010).

No mercado brasileiro de vestuário de segurança, segundo Albuquerque (2013), existe uma real oportunidade de crescimento. Para igualar-se a países como Canadá e Estados Unidos, o Brasil precisaria dobrar o consumo atual. É necessário esclarecer para este estudo que roupas de proteção não são sinônimos de uniformes. A vestimenta de segurança confere proteção a riscos específicos, e são considerados roupas de proteção (EPI). Já um uniforme comum tem a função normalmente de identificar trabalhadores, sem necessidade obrigatória de proteger o usuário.

Podemos citar exemplos de uniformes que são EPI como o vestuário de combate militar e de ação do corpo de bombeiros, segundo Ferreira e Peixoto (2013). Nas duas situações de trabalho, os usuários expõem-se às altas temperaturas colocando suas vidas em risco. Nestes casos, verifica-se a importância e relevância da confecção de roupas de proteção com características antichama, que retardem a propagação do calor e chama através do vestuário, aumentando a segurança do trabalhador em situações de risco.

De acordo com Albuquerque (2013), considera-se resistente a chama a fibra que não se decompõe e mantém suas propriedades físicas em temperaturas acima de 200 graus Celsius. Esse tipo de material tem elevado custo, até 60 vezes mais quando comparado a fibras comuns, tornando inviável o uso em roupas convencionais. Por isso é relevante o estudo de novos materiais desenvolvendo alternativas mais viáveis para o mercado. 


\section{OBJETIVO}

Este trabalho tem como objetivo a obtenção de nãotecidos eletrofiados de poliamida com propriedades antichama como partes constituintes de uniformes técnicos de proteção.

\section{MATERIAIS E MÉTODOS}

O estudo foi realizado no Laboratório de Transferência de Massa (Labmassa) do Departamento de Engenharia Química e Engenharia de Alimentos da Universidade Federal de Santa Catarina.

\subsection{Materiais}

O polímero a ser eletrofiado foi a poliamida 6 e 66. A matéria-prima foi gentilmente cedida pela empresa têxtil Farbe, da cidade de Indaial (SC), Damenny, da cidade de Pomerode (SC), ambas na forma de fio. A empresa Rhodia gentilmente contribuiu com poliamida em forma de resina pura. Os solventes usados foram ácido fórmico, com grau de pureza $88 \%$, fornecedor Biotec, ácido clorídrico, com grau de pureza 36,46\%, fornecedor Synth, dimetilformamida, com grau de pureza 99\%, fornecedor Sigma-Aldrich, cloreto de sódio, com grau de pureza $99 \%$, fornecedor Lafan.

O equipamento de eletrofiação foi composto por uma bomba de infusão para duas seringas da marca insight e gerador de energia de $30 \mathrm{kv}$.

\subsection{Métodos}

Preparação do material a ser eletrofiado: Para obtenção da solução polimérica a matéria-prima foi solubilizada sob agitação magnética constante e temperatura ambiente, até completa dissolução. A Tabela 1 apresenta as condições de solubilização para cada polímero utilizado.

Tabela 1 - Condições de solubilização do polímero.

\begin{tabular}{|c|c|c|c|c|}
\hline Amostra & Material & Tipo & Solvente & Concentração do Polímero \\
\hline $\mathbf{1}$ & PA 66 & Fio & HCOOH 88\% & $5 \%$ \\
\hline $\mathbf{2}$ & PA 66 & Fio & HCOOH 88\% & $10 \%$ \\
\hline $\mathbf{3}$ & PA 66 & Fio & $\mathrm{HCl} \mathrm{10 \%}$ & $10 \%$ \\
\hline $\mathbf{4}$ & PA 66 & Fio & $\mathrm{HCl} \mathrm{50 \%}$ & $10 \%$ \\
\hline $\mathbf{5}$ & PA 66 & Fio & $\mathrm{HCl} \mathrm{50 \%}$ & $50 \%$ \\
\hline $\mathbf{6}$ & PA 6 & Resina & HCOOH 88\% & $10 \%$ \\
\hline $\mathbf{7}$ & PA 66 & Resina & HCOOH 88\% & $10 \%$ \\
\hline $\mathbf{8}$ & PA 66 & Resina & HCOOH 88\% & $15 \%$ \\
\hline
\end{tabular}


Processo de eletrofiação: $O$ processo de eletrofiação foi realizado em temperatura ambiente, com os seguintes parâmetros controlados: voltagem variando entre 20 e $30 \mathrm{kV}$, vazão de infusão do polímero de 0,4 a $1 \mathrm{ml} / \mathrm{h}$ e distância entre agulha e coletor variando de 9 a $17,5 \mathrm{~cm}$. Para viabilizar o processo de eletrofiação, dimetilformamida e/ou cloreto de sódio foram adicionados à solução polimérica.

Análise de microscopia eletrônica de varredura (MEV): A análise morfológica dos nãotecidos produzidos foi realizada por microscopia eletrônica de varredura em um microscópio eletrônico da marca JEOL, modelo JSM-6390LV.

\section{RESULTADOS E DISCUSSÕES}

Neste estudo, discutiremos os resultados encontrados para obtenção de nãotecido de poliamida produzido pela técnica de eletrofiação.

\subsection{Solubilização da poliamida}

A utilização do ácido clorídrico como solvente mostrou-se ineficiente para a dissolução completada poliamida.

Os demais testes de solubilidade foram obtidos com o solvente ácido fórmico, que se mostrou eficiente e rápido, sendo adotado como solvente padrão para os demais experimentos.

\subsection{Eletrofiação}

As amostras de poliamida provenientes de fio têxtil, não tiveram bom desempenho na produção do nãotecido por eletrofiação. Houve atração da solução polimérica para placa coletora, mas não na forma de fibras, apenas na forma de gotas, caracterizando o processo de electrospraying, em que a solução polimérica é pulverizada sob a superfície coletora, impedindo a formação do nãotecido. Os parâmetros da eletrofiação foram variados, de acordo com item 3.2, porém, não se pode identificar qualquer alteração no resultado da obtenção do nãotecido. No intuito de melhorar a condutibilidade foi acrescentado dimetilformamida, porém não houve resultado positivo na formação de fibras.

Em busca do resultado que favoreçam a formação de nanofibras, substituiu-se o fio de poliamida pela resina pura, repetindo-se as condições de eletrofiação. Apesar de, aparentemente, visualizar-se mais material depositado na placa coletora, o resultado permaneceu sem alterações, não formando fibras.

Conforme estudos de Guerrini et al. (2009), a adição de cloreto de sódio favorece a formação das fibras durante processo de eletrofiação. Como no estudo de Guerrini, a melhora das condições do processo com a adição do sal foi imediata, viabilizando a formação do jato e, consequentemente, a formação das fibras de poliamida que se depositaram na placa coletora de forma aleatória. Porém, concentrações de sal acima de $1 \%$ prejudicaram a formação do nãotecido, gerando uma instabilidade no campo elétrico no dispositivo fazendo a fibra estirada retornar à agulha ao invés da placa coletora. 
Nos experimentos com a adição de cloreto de sódio, obteve-se o primeiro resultado positivo na formação do nãotecido. Na concentração de $1 \%$ de $\mathrm{NaCl}$ foi obtida uma manta de nãotecido visualmente uniforme. As imagens foram analisadas por microscopia eletrônica e são apresentadas na Figura 1.

Figura 1 - Microscopia eletrônica de varredura das amostras de poliamida eletrofiada, ampliação de 2000x: a) PA 6; b) PA 66.

(a)

(b)
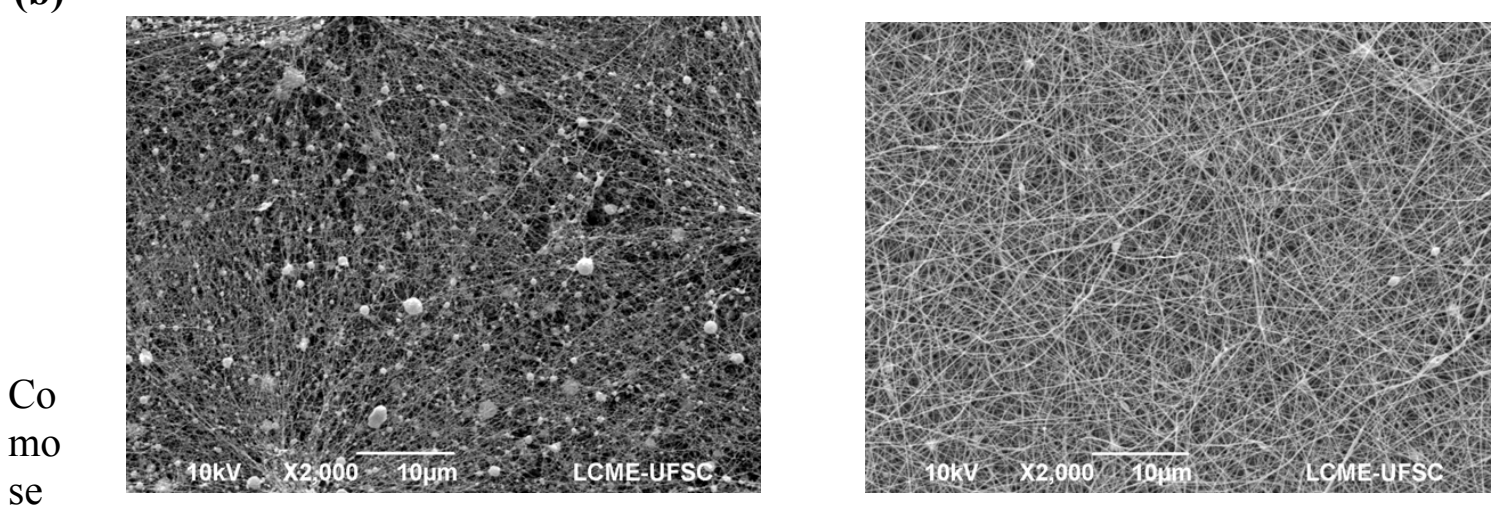

per

cebe nas imagens de $\mathrm{MEV}$, as fibras formadas estão na escala manométrica apresentando regularidade de diâmetros e baixa porosidade. Entretanto, para a poliamiada 6, Figura 1(a), percebe-se a presença indesejada dos beads, que são gotas de polímero não estiradas durante o processo. Apesar da formação das fibras na Figura 1(a), é necessário otimizar o processo, pois as fibras estão demasiadamente finas, o que diminui as características de porosidade e capilaridade do nãotecido formado e por consequência dificulta a liberação de qualquer agente que venha a ser adicionado com objetivo de funcionalizar o tecido, como o agente retardante de chama. Estas fibras demasiadamente finas podem ser devido à baixa massa molar da poliamida 6. Na Figura 1(b), nãotecido de poliamida 66, encontra-se outra situação para o material eletrofiado, com maior uniformidade de diâmetros de fibras e um nãotecido com morfologia mais adequada ao que se espera de um material eletrofiado, sem a presença dos indesejáveis beads. Este nãotecido de fibras regulares e sem beads é um material potencial para continuidades dos estudos com inclusão do componente retardante de chama.

\section{CONCLUSÃO}

Utilizando como matéria-prima a poliamida, estudos foram feitos para obtenção de nanofibras para constituir um nãotecido. $\mathrm{O}$ método escolhido foi a eletrofiação, visando a possibilidade de modificar as propriedades do produto final com aditivos anti-chamas para utilização em uniformes de proteção. Nos experimentos para solução do polímero o ácido clorídrico foi descartado por ser ineficiente, sendo o ácido fórmico adotado como solvente padrão pelo resultado eficaz. Mediante solução pronta, testes foram realizados com variados parâmetros do processo de eletrofiação. A viabilidade do processo de eletrofiação foi alcançado ao adicionar $\mathrm{NaCl}$ na solução polimérica. Analisadas as amostras através de $\mathrm{MEV}$ constatou-se que a manta formada utilizando PA 66 resultou em fibras com diâmetro mais uniforme que a PA 6. Assim, o estudo será continuado com direcionamento no aumento da 
viscosidade da solução utilizando a poliamida 66 em busca de fibras com maior diâmetro e melhor uniformidade para posterior adição do agente repelente de chama.

\section{REFERÊNCIAS}

ALBUQUERQUE, S. M. Estudo comparativo do comportamento da costura em tecido que retarda a chama, submetida ao calor e a chama. Dissertação apresentada a Escola de Artes e Humanidades da Universidade de São Paulo. São Paulo, 2013.

COSTA, Rodrigo G. F., Eletrofiação de Polímeros em Solução. Parte I: Fundamentação Teórica. Polímeros, vol. 2, 2, p. 170-177, 2012.

GUERRINI, L.M.; BRANCIFORTI, M. C.; CANOVA, T.; BRETAS, R. E. S. Electrospinning and Characterization of Polyamide 66 Nanofibers With Different Molecular Weights. Mat. Reser., v. 12, 2, p. 181-190, 2009.

GOMES, P. H., Implementação da técnica de eletrofiação de filmes poliméricos. Universidade Federal de Alfenas, 2014.

FERREIRA, J. A. S.; PEIXOTO, A. F. V. Roupas de Proteção Individual: um horizonte importante para as indústrias têxteis e de confecção do Brasil. Redige v.4, n.01, 2013.

RIGBY, D. Technical Textiles and Nonwovens: World Market Forecasts to 2010. Disponível em $<$ http://www.fibre2fashion.com/industry-article/pdffiles/Technical-Textiles-andNonwovens.pdf $>$. Acesso em: 27 de fevereiro de 2015.

SANTOS, C. R., BRANCIFORTI, M. C., CANOVA, T.. Preparação e caracterização de nanofibras de nanocompósitos de poliamida 6,6 e argila montmorilonita. Polímeros, v. 21, 5, p. 398-408, 2011.

XIA Y.; LI D. Electrospinning of Nanofibers: Reinventing the Wheel?. Adv. Mater, v.16, p. 1151-1170, 2004. 